\title{
Identification and Functional Characterization of the GALACTINOL SYNTHASE (MoGolS1) Gene in Melissa officinalis Plants
}

\author{
Jun Hyeok Kim ${ }^{\dagger}$, Acktar Mohammad Hossain’, Nahyun Kim, Dong Ho Lee, and Hojoung Lee* \\ Division of Biotechnology, College of Life Sciences and Biotechnology, Korea University, \\ 1, 5-ka Anam-dong, Sungbuk-ku, Seoul 136-713, Republic of Korea
}

Received October 28, 2011; Accepted November 1, 2011

\begin{abstract}
Galactinol and rafinose accumulation in plants is associated with stressful environmental conditions such as cold, heat, or dehydration by the action of galactinols synthase (GolS) in the raffinose family of oligosaccharides biosynthetic pathway from UDP-galactose. Moreover, several reports mentioned that GolS transcription is up regulated by various environmental stresses like cold, heat, dehydration. Therefore, to determine whether MoGolS1 was induced with the abiotic stress we analyzed the expression pattern of the gene under various abiotic stresses like heat, cold, abscisic acid, sucrose and salt concentration in the lemon balm plants grown in standard MS medium. The MoGolS1 gene was 981-bp in length encoding 326 amino acids in its sequence and shared 77 and $76 \%$ sequence similarity with Arabidopsis thaliana galactinol synthase4 (AtGolS4) and AtGolS1 genes respectively. The MoGolS1 gene was strongly expressed by the abiotic stress induced by sucrose, ABA or heat shock. It was also expressed in responses to cold, manitol and $\mathrm{NaCl}$. MoGolS1 gene induction with various stresses may be possible for itscrucial function in abiotic stress tolerance in plants, providing a good engineering target for genetic engineering.
\end{abstract}

Key words: abiotic stress, abscisic acid, galactinol synthase, Melissa officinalis, sucrose

\section{Introduction}

Soluble sugars including raffinose family oligosaccharides (RFOs) have been implicated in mitigating the effects of environmental stresses on plants [Downie et al., 2003]. Their accumulation in plants is associated with stressful environmental conditions such as cold, heat, or dehydration [Santarius, 1973; Santarius and Milde, 1977; Hinesley et al., 1992; Ashworth et al., 1993; Wiemken and Ineichen, 1993; Bachmann et al., 1994; Taji et al., 2002] when they presumably assist sucrose in ameliorating plant stress [Zhao et al., 2004]. It is also proposed to play significant roles in protecting cellular integrity during desiccation or dehydration and provides substrates for energy generation during seed germination [Downie et al., 2003].

Galactinol is reported to be involved in tolerance to drought, high salinity and cold stresses which is produced from UDP-Gal and myo inositol by the action of Galactinol synthase (GolS). Because the only known function of galactinol is the formation

J. H. Kim ${ }^{\dagger}$ and A. M. Hossain ${ }^{\dagger}$ contributed equally.

*Corresponding author

Phone: +82-2-3290-3006; Fax: +82-2-3290-3508

E-mail: lhojoung@korea.ac.kr

http://dx.doi.org/10.3839/jabc.2011.040 of RFOs [Saravitz et al., 1987; Liu et al., 1995], which is putatively the committed enzyme step in the RFO biosynthetic pathway [Pridham and Hassid, 1965; Saravitz et al., 1987; Smith et al., 1991; Peterbauer and Richter, 2001] from UDPgalactose. Thus GolS catalyses the first step in the biosynthesis of galactinol and RFO from UDP-galactose and plays regulatory roles in carbon partitioning between sucrose and RFOs [Saravitz et al., 1987] under the abiotic stress conditions, and that galactinol and rafinose function as osmoprotectants in droughtstress tolerance of plants.

The GolS gene is thought to play potential roles in catalyzing metabolic steps, and provides an important experimental tool for manipulating the level of RFOs as osmoprotectants. These gene products are reported to function in the accumulation of osmoprotectants; detoxification, protection of cells; protein turnover; stress-signalling pathways; and transcriptional regulations [Bohnert et al., 1995; Ingram and Bartels, 1996; Bray, 1997; Shinozaki and Yamaguchi-Shinozaki, 1997].

GolS activity in kidney bean seeds is increased on exposure of plants to cold, and the expression of GolS genes is induced by cold stress in Arabidopsis and Ajuga reptans plants [Liu et al., 1995; Sprenger and Keller, 2000]. During cold acclimation, RFOs accumulate in leaves of A. reptans [Bachmann et al., 1994]. AtGolS1 and AtGolS2 is reported to induced by drought and high-salinity stresses, while AtGolS3 is induced by cold. 
Galactinol Synthase gene of Coptis japonica (CjGols) is involved in berberine tolerance [Takanashi et al., 2008]. Over expression of Arabidopsis GolSl and GolS2 had increased levels of galactinol and raffinose in the leaves compared with wildtype plants under control growth conditions in the transgenic plants were correlated with increased tolerance to methyl viologen (MV) treatment and salinity or chilling stress probably by scavenging hydroxyl radicals as a novel function to protect plant cells from oxidative stress [Taji et al., 2002; Nishizawa et al., 2008]. Furthermore, GolS1 in Arabidopsis is reported as a novel heat shock factor (HSF) target gene, which is responsible for heat stress-dependent synthesis of raffinose, [Panikulangara et al., 2004] and may have influence in heat shock tolerance in the plants. Although the roles of GolS genes have been elucidated in many plants, nothing is known about it in the Lemon balm (Melissa officinalis), a very important medicinal plant species. As a result, we therefore decided to report here after identification and functional characterization in wild type lemon balm and transgenic Arabidopsis plants.

\section{Materials and Methods}

Plant growth conditions and treatments. In vitro regenerated containerized lemon balm (M. officinalis L.; Lamiaceae) plants grown in solid Murashige and Skoog (MS) medium $4 \mathrm{~g} / \mathrm{L}$ Murashige and Skoog, 2\% sucrose solidified with $7 \mathrm{~g} / \mathrm{L}$ agar at $\mathrm{pH} 5.7$ prior to autoclaving) were used for this study. Approximately $2 \mathrm{~cm}$ long explants, including shoot tip and one pair of leaves, were transferred to the culture medium and incubated in a controlled environment of $250.2^{\circ} \mathrm{C}$ in standard photoperiod $(16 \mathrm{~h}$ light and $8 \mathrm{~h}$ dark) with a light intensity of $40 \mu \mathrm{mol} / \mathrm{m}^{2} \mathrm{~s}$ provided by cool-white florescent lamps. For stress treatment, explants were grown in solid MS medium for 15 days and subjected to various treatment conditions. To examine the effects of sucrose concentration on gene expression, uprooted (15 days after planting) plants were exposed to liquid MS medium supplemented with $250 \mathrm{mM}$ sucrose for $0,6,12$ or $24 \mathrm{~h}$. The effect of abscisic acid (ABA) was determined by placing the uprooted plants into liquid medium having $100 \mu \mathrm{M}$ ABA for $0,1,3$ or $6 \mathrm{~h}$. The plants were cultured in medium with $300 \mathrm{mM} \mathrm{NaCl}$ or Manitol for $0,1,3$ or $6 \mathrm{~h}$ for assessing the effect of salts stress on the gene expression. For heat shock treatment, the plants grown in solid medium were placed at $37^{\circ} \mathrm{C}$ for $0,1,3,6$ or $12 \mathrm{~h}$. Cold stress was provided by placing the plants in container at $4^{\circ} \mathrm{C}$ for $0 \mathrm{~h}, 12 \mathrm{~h}, 1$ day, 2 day, 3 day or 6 day. Harvested roots, shoots, and leaves were frozen in liquid nitrogen and stored at $-80^{\circ} \mathrm{C}$ until analyzed. $\mathrm{T}_{1}$ generation seeds of transgenic Arabidopsis were surface sterilized and stratified at $4^{\circ} \mathrm{C}$ for 3 days and allowed to germinate on MS medium at $23 \pm 1^{\circ} \mathrm{C}$ under a $16 \mathrm{~h}$ light $/ 8 \mathrm{~h}$ dark cycle.

All of the chemicals used in this study were purchased from Sigma Aldrich (St. Louis, MO) except for the ABA and fluridon, which were purchased from Duchefa Biochemie (Postbus, Haarlem, The Netherlands), random primer DNA labeling system from Invitrogen (San diego, CA) and the ethanol, which were purchased from Merck (Darmstadt, Germany).

Lemon balm cDNA library construction (Commercial service). At the beginning of this study there was no information about genomic or expressed sequence tag (EST) for the lemon balm in the database (http://www.ncbi.nih.gov/BLAST/). Therefore we prepared the EST from the lemon balm cDNA library. Total RNA was purified with TRIzol from the lemon balm leaves grown with $250 \mathrm{mM}$ sucrose in MS medium for 20 days. Poly $(\mathrm{A})^{+}$was purified with PolyA Tract mRNA isolation system (Promega, Madison, WI) and cDNA was synthesized with cDNA synthesis kit (Stratagene, La Jolla, CA). cDNAs were directionally cloned with EcoRI on the 5' and XhoI on the 3 ' end into the Uni-ZAP XR vector (Stratagene). The vector containing the DNA was then transformed into phage and Primary Lambda Phage Library was constructed by Gigapack III Gold Packaging Extract (Stratagene). EST was established by transforming into the host cells SOLR strain and nucleotide sequencing of the genes.

Amino acid sequence comparison and phylogenetic analysis. The MoGolSl gene was identified from the lemon balm EST following nucleotide sequencing with BLASTN program (http://www.ncbi.nlm.nih.gov). Nucleotides of MoGolS1 genes was translated into amino acids by using ExPASy translation tool (www.expasy.ch/tools/dna.html). The nucleotide and amino acid sequences of MoGolSl and its related genes from other plant species were obtained from the nucleotide and protein databases of NCBI (http://www.ncbi.nlm.nih.gov). Amino acid sequences were then compared and phylogenetic trees were constructed using a multiple sequence alignment program, CLUSTAL W software (http://workbench.sdsc.edu).

RNA-gel blot analysis. Wild type lemon balm explants were grown on a standard MS medium for 15 days and exposed to various treatments for required period of time. Total RNA was purified using aurintricarboxylic acid (ATA) and lithium chloride [Lee et al., 2002] or RNeasy Plant Mini kit (QIAGEN, Hilden, Germany). Northern analysis was performed following the procedure reported Kwon et al. [2007]. Fifteen microliter of total RNA was fractioned by electrophoresis on $1.2 \%(\mathrm{w} / \mathrm{v})$ agarose gels (containing $1 \times 3$-(N-morpholino) propanesulfonic acid (MOPS) and $0.66 \mathrm{M}$ formaldehyde) and transferred on to a Hybond nylon membrane (Amersham, Buckingamshire, UK) with $20 \times$ SSC by capillary action and UV cross linked. For Northern hybridization, DNA probes for MoGolS1 was 
amplified with gene specific primers (5' GCGCAGTAGTGAAC AACTTC 3' forward and 5' CTCGACACACCTGATGGCTA 3' reverse to amplify 383-bp fragment of MoGolS1 from lemon balm cDNA. Probes were labeled with $\alpha-{ }^{32} \mathrm{P}$ dCTP using a random primer DNA Labeling System (Invitrogen). After prehybridization for $1 \mathrm{~h}$, the hybridization of $\alpha-{ }^{32} \mathrm{P}$-random-primed probes onto RNA blots was carried out at $65^{\circ} \mathrm{C}$ overnight. The RNA blot was then washed twice in $1 \%$ SSC, $0.1 \%$ SDS and once in $0.1 \% \mathrm{SSC}, 0.1 \% \mathrm{SDS}$ at $42^{\circ} \mathrm{C}$ prior to autoradiography.

Molecular cloning of MoGolS1 gene. The 5' and $3^{\prime}$ Rapid Amplification of cDNA Ends (5'- and 3'-RACE) of candidate genes were performed (Commercial service) to identify open reading frame $(\mathrm{ORF})$. Full length DNA fragments were then amplified from the lemon balm cDNA with gene specific primers (5'ATGGGGAGGAAGAAAAGGCA 3' forward and 5' AGCAGCAGAAGGGGCAGGTA 3' reverse for MoGolsl) and inserted into the TOPO entry vector (Spectinomycin resistance) and transformed into $E$. coli chemically competent cells through Gateway Cloning System (Invitrogen) following manufacturer's recipe. After confirmation of successful transformation by colony polymerase chain reaction (PCR) (with M13 forward primers and gene specific reverse primers) and nucleotide sequencing the genes were cloned into the destination vector PMDC 32 for over expression and PMDC83 for 35S::gene::green fluorescent protein (GFP) localization using recombinant kits (invitrogen) and transformed into E. coli (DH5 $\alpha$ ) through electroporations. The transformation was confirmed again with colony PCR (with gene specific forward and reverse primers) and nucleotide sequencing. Finally the genes were inserted into the Agrabacterium tumefaciens and were transformed with Col-0 Arabidopsis plants by floral dipping. Transgenic $T_{1}$ Arabidopsis plants were screened with hygromycine resistance.

Quantification of galactinol. The galactinol dihydrate standard and plant extracts treated with six different conditions were analyzed by ultra performance liquid chromatography/ quadrupole time-of-flight mass spectrometer (UPLC/Q-Tof MS, Bio-Rad, Berkeley, CA). UPLC was performed using a Waters ACQUITY UPLC ${ }^{\mathrm{TM}}$ system (Waters Corp., Milford, MA). The chromatography was performed on an Waters ACQUITY BEH HILIC column $(100 \mathrm{~mm} \times 2.1 \mathrm{~mm}, 1.7 \mu \mathrm{m})$. The mobile phase consisted of (A) $0.1 \%$ formic acid in distilled water and (B) $0.1 \%$ formic acid in acetonitrile. The Ultra Performance Liquid Chromatography (UPLC) gradient condition was optimized as follows: linear gradient from 90 to $30 \%$ B (0-3.0 min), held at $30 \%$ B (3.0-3.7 min), and returned to the initial condition at $90 \%$ B (3.7-5.0 min). The flow rate was $300 \mu \mathrm{L} / \mathrm{min}$ and the injection volume was $5 \mu \mathrm{L}$. The column and autosampler was maintained at 35 and $15^{\circ} \mathrm{C}$, respectively. The Q-Tof MS was performed using Q-TOF Micro mass detector (Waters,
Manchester, UK). Mass spectra of all samples were acquired using electrospray ionization in negative ion mode and ion preparation in single ion monitoring mode. The capillary voltage, sample cone voltage, extraction cone voltage, desolvation temperature, and source temperature were set at $2800,28,1.2 \mathrm{~V}$, $300,100^{\circ} \mathrm{C}$, respectively. Leucine-enkephalin was used as a reference ion to measure accurate mass. Data acquisition and processing were conducted with MassLynx version 4.1 (Waters). QuanLynx software (ver. 4.0, Micromass, Manchester, England) was used for generation of a calibration curve and quantification of analytes. For quantitative analysis of galactinol, standard solutions at five concentration levels between 0.05 and $5 \mu \mathrm{g} / \mathrm{mL}$ were used. Linearity of the multi-point calibration curves was determined by plotting the peak area ratios of the analyte using QuanLynx software. The galactinol levels in plant extracts treated with six different methods were quantified based on the calibration curve.

\section{Results}

Identification of lemon balm Galactinol Synthase gene. During EST sequencing, we noticed interesting gene GolS in the lemon balm cDNA library which was very similar to other GolS genes from Arabidopsis and other plants. We decided to study on that gene too in the present research work. By using reverse transcription (RT)-PCR and 5'-3'- rapid amplification of cDNA ends (RACE), we obtained the full length galactinol synathse genes from lemon balm (M. officinalis L.), which we named MoGolSl genes. The MoGolS1 was 981-bp in length containing open reading frame (ORF) encoding 326 amino acid in its sequence. The amino acid comparison shows that it shared 77 and $76 \%$ amino acid sequence with Arabidopsis thaliana galactinol synthase (AtGolS)4 and AtGolSl genes respectively. The MoGolS1 also shares a considerable percentage (60-70\%) of amino acid identity with GolS genes from other plants having distinct characteristics of hydrophobic pentapeptides (APSAA) at the conserved carboxy terminus of the sequences (Fig. 1A). A phylogenetic tree for important plant GolS genes including MoGolS1 was constructed by using the full-length deduced amino acid sequencing (Fig. 1B).

MoGolS1 gene transcription is up-regulated by sucrose concentration. In our preliminary experiment we observed maximum transcription of $\mathrm{MoGolSl}$ gene in the plants exposed to $250 \mathrm{mM}$ sucrose (data not shown). We therefore treated the plants in liquid medium with $250 \mathrm{mM}$ sucrose for $0,6,12$ or $24 \mathrm{~h}$ prior to purify total RNA for northern analysis. Sucrose concentration as well as treatment duration significantly enhanced the transcription levels of MoGolS1 genes in the wild type lemon balm plants. Figure 2 (A and B) exhibits that MoGolS1 gene was predominantly expressed in leaves 


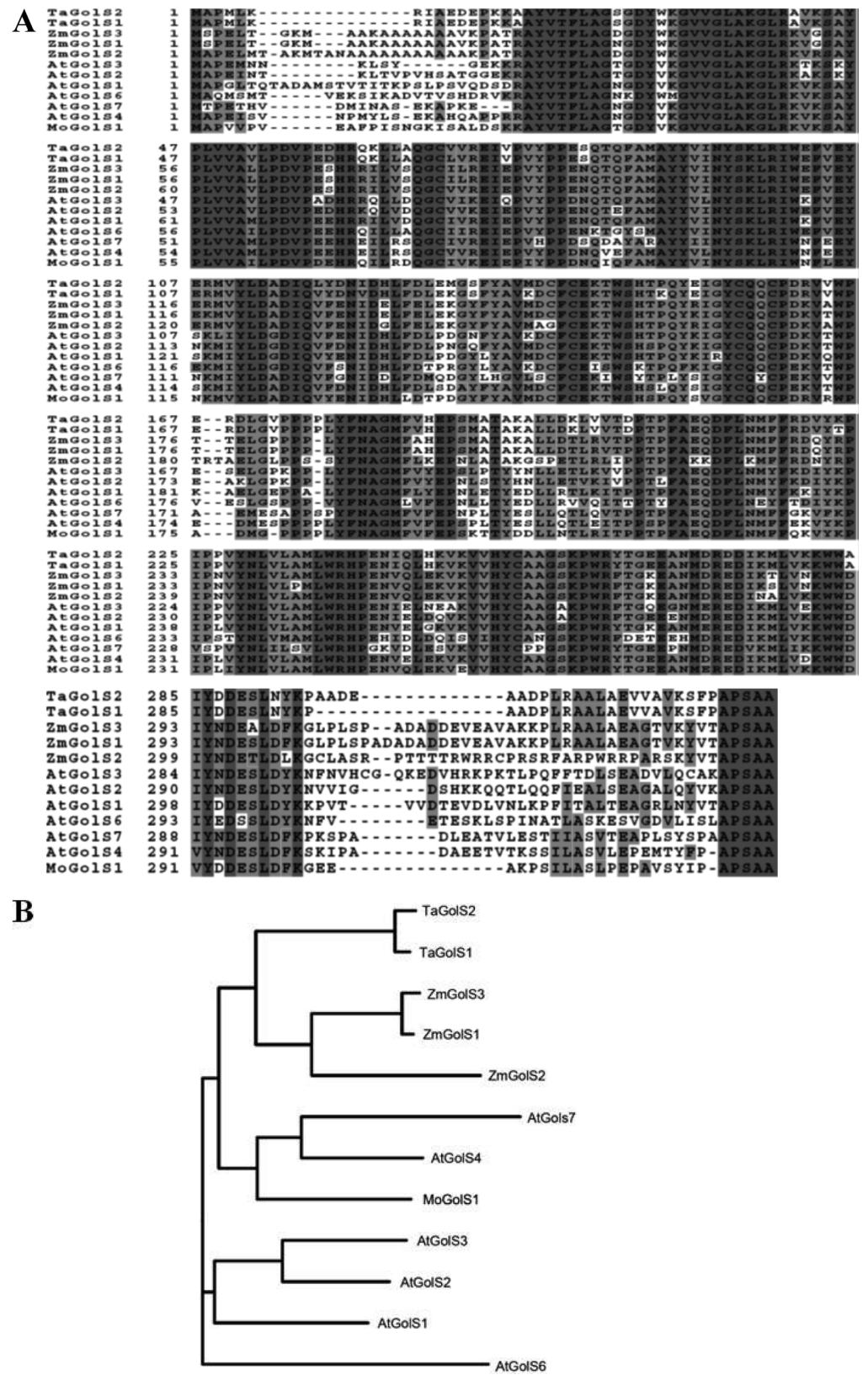

Fig. 1. Multiple sequence alignment and phylogenetic tree of $\boldsymbol{G o l S}$ amino acids from various higher plants. (A) Deduced amino-acid sequence comparison of the MoGolSl with GolS from other plant species (indicated in the left margin) by CLUSTAL W program. The identical residues are shaded in dark gray with black letters. Residues with at least $75 \%$ to $50 \%$ conservation are shaded in light gray. Amino acid residue numbers are indicated on the left in the alignment. Triticum aestivum GolS1 (TaGolS1; Accession AB250356.1), T. aestivum GolS2 (TaGolS2; AB250357.1), Zea Mays GolS1 (ZmGolS1; NM_001112278.1), Z. mays GolS2 (ZmGolS2; NP_001105749.1), Z. mays GolS3 (ZmGolS3; EU962434.1), Arabidopsis thaliana GolS1 (AtGolS1; AB062848.1), A. thaliana GolS2 (AtGolS2; AB062849.1), A. thaliana GolS3 (AtGolS3; AB062850.1), A. thaliana GolS4 (AtGolS4; NM 104734.3), A. thaliana GolS6 (AtGolS6; NP 567741.2), A. thaliana GolS7 (AtGolS7; NM 104732.1), Melissa officinalis GolS1 (MoGolSl). (B) A phylogenetic tree derived from the amino acid sequence comparison in (A) above.

irrespective to the treatment. However, the expression level was significantly higher in the sucrose treated leaves for $24 \mathrm{~h}$ followed by $12 \mathrm{~h}$ than the control leaves (Fig. 2B). Although there was a constitutive expression of the gene in the roots, no transcription was detected in the stem tissues whether the plants were treated with sucrose.

ABA enhances the MoGolS1 transcription in lemon balm plants. As we know that high concentration of sucrose induces oxidative stress to the plants mediated by $\mathrm{ABA}$ dependent or independent pathway, we wondered whether the ABA induced the transcription level of MoGolS1 gene in the lemon balm plants. We treated the uprooted lemon balm plants in liquid MS medium supplemented with $100 \mu \mathrm{M}$ ABA for $0,1,3$ or $6 \mathrm{~h}$ before extracting the total RNA for northern hybridization. Figure $3 \mathrm{~A}$ shows that MoGolS1 transcription level was significantly enhanced with the abiotic stress induced by ABA 
A S

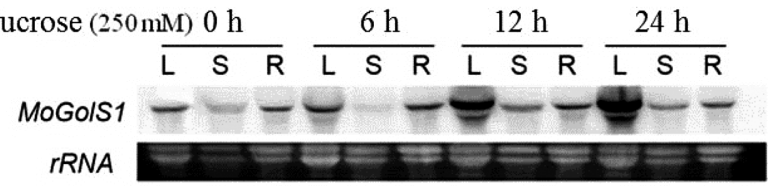

B

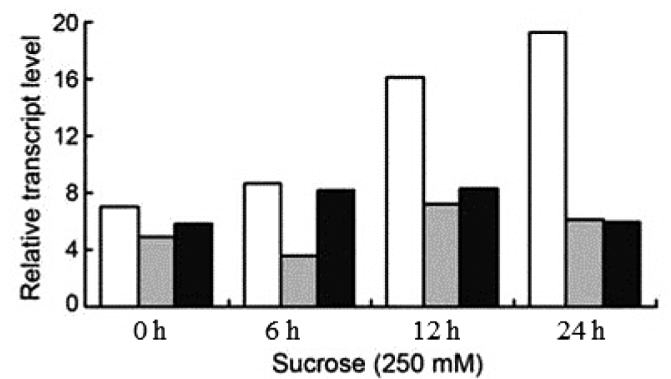

Fig. 2. Northern blot analysis of MoGolS1 genes in wild-type lemon balm leaves (L), stems (S), and roots (R). Lemon balm explants were grown on standard MS medium for 15 days and treated in liquid MS medium supplemented with $250 \mathrm{mM}$ sucrose for $0,6,12$ or $24 \mathrm{~h}$. Total RNA was extracted with aurintricarboxylic acid (ATA) and lithium chloride and separated by electrophoresis on a formaldehyde agarose gel followed by transferring to a nylon membrane. Northern blots (15 $\mu \mathrm{g}$ per lane) were hybridized with $\alpha-{ }^{32} \mathrm{P}$ labeled cDNA probes of MoGolS1 (A). Relative transcription level of the MoGolS1 (B) genes was calculated by Multi Gauge software (version 3, Fujifilm corp, Tokyo, Japan) in leaves (white bar), stems (shaded bar) and roots (black bar) as ratio to the blank. Equal loading of RNA samples in each lane was verified by ethidium bromide staining of ribosomal RNA shown beneath the northern blots.

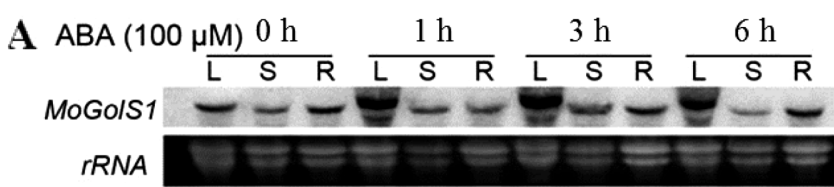

$\mathbf{B}$

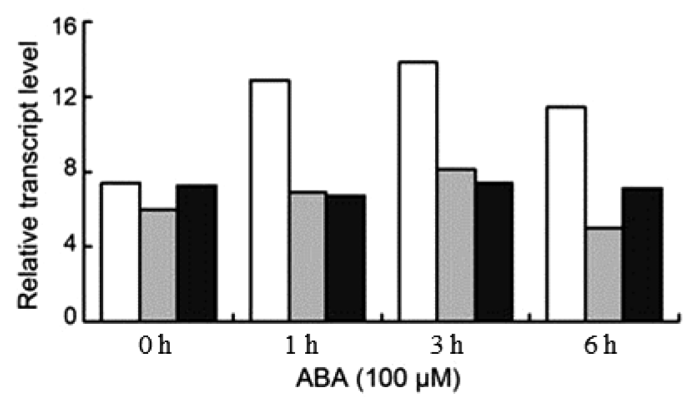

Fig. 3. Effects of ABA on MoGolS1 gene expression in lemon balm plants. After 15 days of growth in solid MS medium, lemon balm plants were treated in liquid medium supplemented with $100 \mu \mathrm{M}$ ABA for $0,1,3$ or $6 \mathrm{~h}$. Total RNA was purified from leaf (L), root (R) and stem (S) tissues with aurintricarboxylic acid (ATA) and lithium chloride and northern hybridization was performed with $\alpha-{ }^{32} \mathrm{P}$ labeled cDNA probes of MoGolS1 (A). Equal loading of RNA samples (15 $\mu \mathrm{g}$ in each lane) was verified by ethidium bromide staining of ribosomal RNA shown beneath the northern blots. The transcript level of MoGolS1 (B) was determined in leaves (white bar), stem (shaded bar) and roots (black bar) as ratio of sample transcription to the blank.

over the incubation periods. The transcription started within very short period of incubation even within $1 \mathrm{~h}$ of treatment. Like sucrose, the MoGolS1 expression level was considerably higher in leaf tissues compared to the stem and roots due to the ABA
A Mannitol (300 mM)

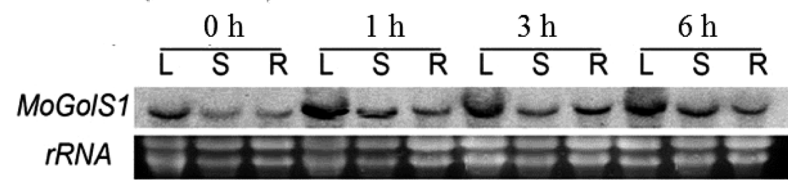

B

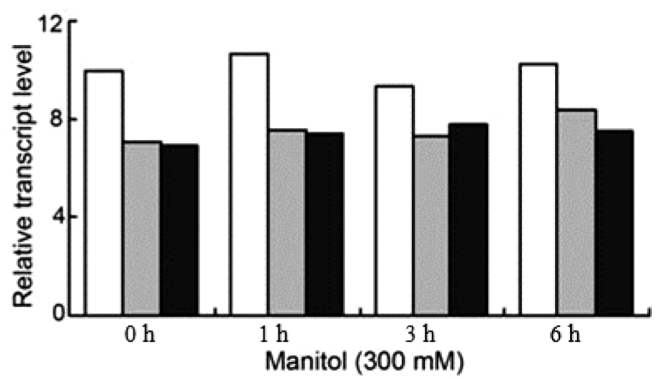

Fig. 4. Transcription levels of MoGolS1 gene in lemon balm plants in response to mannitol. Whole plants were treated with $300 \mathrm{mM}$ manitol in liquid medium for $0,1,3$, or $6 \mathrm{~h}$. Total RNA was purified from the leaves (L), stems (S) and roots (R) and probed with MoGolS1 (A) DNA fragments. Ethidium bromide-stained gel images of rRNA bands are shown beneath the northern blots. Relative transcript levels of MoGolS1 (B) gene in leaves (white bar), stems (shaded bar) and roots (black bar) was shown as ratio of sample transcript to the blank.

treatment. Expression level of the gene in root tissue was almost constant irrespective to the treatments (Fig. 3B). However, transcription was gradually down-regulated in the stem tissues over the incubation period and it was distinct after $3 \mathrm{~h}$ of the treatment. This data implicated that the sucrose induced induction of MoGolS1 gene in lemon balm plants might be ABA dependent.

MoGolS1 gene expression in response to Manitol, $\mathrm{NaCl}$, cold or heat. Since, AtGolS1 and AtGolS2 gene, two homolog of $M o G o l S 1$ are reported to induce with dehydration and high salinity [Taji et al., 2002], we examined whether the MoGolS1 was expressed by dehydration stress induced by the application of manitol and high salinity with $\mathrm{NaCl}$. As expected, the transcription level of the MoGolSl gene was markedly enhanced in the leaves treated with maintol for $1 \mathrm{~h}$ and $\mathrm{NaCl}$ after $3 \mathrm{~h}$ of incubation in the treatment medium (Fig. 4A and 5A). The maximum transcription of MoGolS1 was detected just after $1 \mathrm{~h}$ of incubation in manitol and $6 \mathrm{~h}$ in $\mathrm{NaCl}$ indicates that the transcription of MoGolS1 in the manitol was faster than the $\mathrm{NaCl}$. Although irregular, weak expression of the gene was also detected in the stem tissues treated with both manitol and $\mathrm{NaCl}$ without much difference. The transcription of MoGolS1 in the root tissue was weak and constitutive (Fig. 5B).

To determine whether the cold stress enhanced the transcription level of MoGolS1 gene in the lemon balm leaves, we treated the plants at $4^{\circ} \mathrm{C}$ prior to purify of total RNA. From the northern blot analysis, it was observed that the transcription level of MoGolS1 gene increased in the leaves treated for $12 \mathrm{~h}$ or 1day in cold. The transcription level of the gene after 2 days of cold treatment was 


\section{A $\mathrm{NaCl}(300 \mathrm{mM})$}

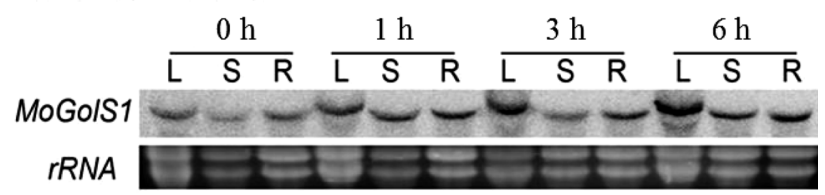

B

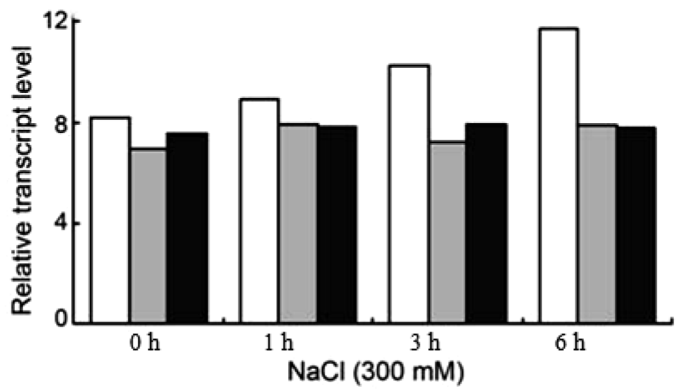

Fig. 5. Expression of MoGolS1 gene in response to $\mathrm{NaCl}$. Total RNA was purified from the leaves (L), stems (S) and roots (R) treated with $300 \mathrm{mM} \mathrm{NaCl}$ for $0,1,3$ or $6 \mathrm{~h}$ in liquid medium. Northern blot analysis was carried out with RNA blot with $\alpha-{ }^{32} \mathrm{P}$ labeled MoGolS1 (A) DNA probes. Equal loading of RNA samples $(15 \mu \mathrm{g}$ in each lane) was verified by ethidium bromide staining of ribosomal RNA shown beneath the northern blots. The transcript level of MoGolS1 (B) was determined in leaves (white bar), stems (shaded bar) and roots (black bar) as ratio of sample transcript to the blank.

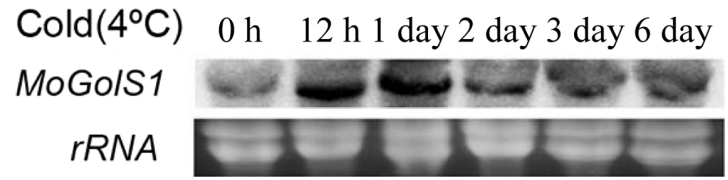

Fig. 6. Cold induced transcription of MoGolS1 and MoMYB3 genes in lemon balm leaves. Total RNA was purified from the leaves treated with cold $\left(4^{\circ} \mathrm{C}\right) 0 \mathrm{~h}, 12 \mathrm{~h}, 1$ day, 2 day, 3 day or 6 day. Northern hybridization analysis was carried out with RNA blot with $\alpha-{ }^{32} \mathrm{P}$ labeled MoGolS1 DNA probes. Equal loading of RNA samples (15 $\mu \mathrm{g}$ in each lane) was verified by ethidium bromide staining of ribosomal RNA shown beneath the northern blot.

irregular in pattern (Fig. 6A). One of the homolog of the MoGolSl, the AtGolSl is known as a Nobel heat shock factor target gene, induced even in wild type Arabidopsis plants after heat stress [Panikulangara et al., 2004]. We therefore investigated whether our GolS1 gene (MoGolS1) was induced with heat shock treatment. Lemon balm plants (15 days after planting them in the MS medium) were treated with heat stress at $37^{\circ} \mathrm{C}$ for $0,1,3,6$ or $12 \mathrm{~h}$ before extracting total RNA from leaf, stem and root tissues. It was noticed that heat tress greatly enhanced the MoGolS1 gene expression level in the lemon balm leaves after $3 \mathrm{~h}$ of incubation (Fig. 7A and B). Unlike sucrose or ABA treatment, considerable increasing of transcription level was also observed in the roots after $1 \mathrm{~h}$ of incubation period. However, the expression level of MoGolSl gene in the stem tissue was almost similar irrespective to the treatment durations.

Galactinol dehydrate level is dereased in the lemon balm leaves. Galactinol dihydrate standard was analyzed in the negative ion mode, and both galactinol and galactinol dihydrate

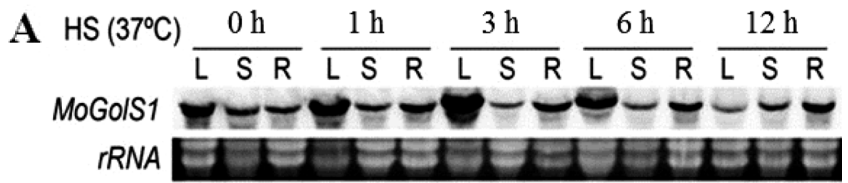

B

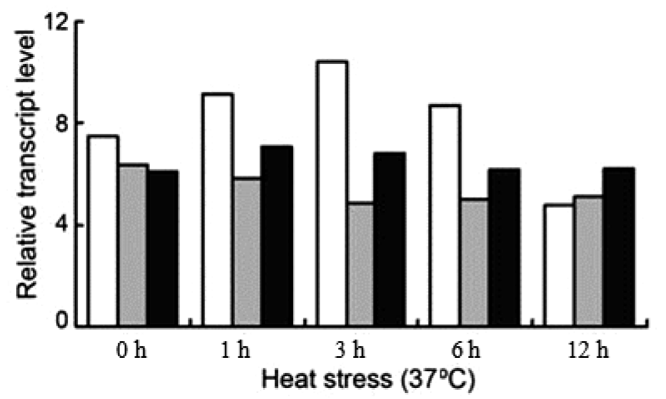

Fig. 7. MoGolS1 gene expression in lemon balm plants under heat stressed condition. Northern blot analysis was carried out on RNA blot (15 $\mathrm{g}$ per lane) purified from wild-type lemon balm leaves (L), stems (S), and roots (R) treated with heat stress (HS) at $37^{\circ} \mathrm{C}$ for 0,1 , 3 , 6 or $12 \mathrm{~h}$ with $\alpha-{ }^{32} \mathrm{P}$ labeled cDNA probes of MoGolS1 (A). Relative transcript levels of MoGolS1 (B) in leaves (white bar), stems (shaded bar) and roots (black bar) shown was calculated as ratio of the sample transcript to the blank.

were detected at 341 and $377 \mathrm{Da}$ as $[\mathrm{MH}]^{-}$ions, respectively. Based on the mass spectrum, galactinol was chosen to be used for quantification since it showed higher ion intensity compared to galactinol dehydrate. LC/MS analysis as a single ion monitoring (SIM) at $m / z 341$ on a standard compound was performed to identify galactinol. Galactinol dihydrate standards were prepared at five different concentration levels, namely 5,1 , $0.5,0.1,0.05 \mu \mathrm{g} / \mathrm{mL}$. Calibration curve was generated with relative peak areas against concentration using QuanLynx software. The curves showed good linearity and the concentration coefficient was found to be in the range of 0.9996. To quantitate the changes in the level of galactinol depending on six different treatment methods, standard compound was identified in plant extracts using retention time and $\mathrm{m} / \mathrm{z}$ value by LC/MS analysis. Detected peak areas of analytes with unknown concentrations were applied to the fitted calibration curve, and the galactinol concentrations of each sample were calculated. As shown in Fig. 8 , the concentrations of galactinol were decreased in sucrose, $\mathrm{ABA}, \mathrm{NaCl}$, mannitol, heat or cold when compared to the control.

\section{Discussion}

Through EST sequencing, we identified Gols gene (MoGolSl) from lemon balm cDNA library. Plant galactininol synthase genes play multiple roles in the defense mechanisms to protect the plants from various stresses and adverse environmental conditions. We observed that the MoGolS1 transcription was significantly up regulated in the leaves treated with $250 \mathrm{mM}$ sucrose for 12 to $24 \mathrm{~h}$ compared to the control 
leaves (Fig. 2A and B). Although there was no report about the transcriptional activation of GolS1 gene with the higher concentration of sucrose, reports indicate that elevated level of sucrose induces osmotic stress to the plants [Javed and Ikram., 2008] which might be responsible for the sucrose induced transcription of the MoGolSl gene in the lemon balm leaves since Liu et al. [1995] mentioned the accumulation of GolS in response to the osmotic stress in plants. Moreover, Nagira et al. [2006] reported that elevated sucrose concentration (7\%) increased the endogenous ABA level in the regenerated torenia plants. The osmotic stress induced by sucrose in the plants is proposed either ABA dependent or independent. To elucidate the factors affecting the sucrose induced elevated transcription of GolSl in the lemon balm leaves, we treated lemon balm plants with $100 \mu \mathrm{M} \mathrm{ABA}$ for various period of time and performed northern hybridization. As expected, we noticed that the transcription level of the GolSl was strongly up regulated in the lemon balm leaves treated with ABA for 1 or $3 \mathrm{~h}$ (Figs. $3 \mathrm{~A}$ and B) while Taji et al. [2002] reported a week induction of AtGolS1 and $A t G o l S 2$ by ABA but not $A t G o l S 3$.

There are reports that other stresses also enhanced the GolS gene transcription. For examples, Taji et al. [2002] reported that AtGolSl and AtGolS2 was induced by drought and high salinity but $A t G o l S 3$ was induced by the cold stress, while Panikulangara et al. [2004] mentioned that Arabidopsis GolS1 was heat inducible. To determine whether other types of abiotic stress also induced MoGloSl transcription in the lemon balm plants we carried out northern hybridization purifying RNA from lemon balm leaves, stems and roots treated with $300 \mathrm{mM}$ manitol or $\mathrm{NaCl}$. The results show that transcription level of the MoGolS1 gene was markedly enhanced in the leaves treated with maintol after $1 \mathrm{~h}$ and $\mathrm{NaCl}$ after $3 \mathrm{~h}$ of incubation in the treatment medium (Figs. 4A and 5A). The maximum transcription of MoGolSl was detected just after $1 \mathrm{~h}$ of treatment in manitol and $6 \mathrm{~h}$ in $\mathrm{NaCl}$ indicates that the transcription of MoGolSl in the manitol was faster than the $\mathrm{NaCl}$. Although there was no report about the transcription of GolS gene by manitol, strong induction of AtGolS2 was reported by $250 \mathrm{mM} \mathrm{NaCl}$ for 2-8 h [Taji et al., 2002]. As mentioned by Taji et al. [2002] and Panikulangara et al. [2004] that GolS gene also induced by the heat and cold stress, we treated the lemon balm plants with heat $\left(37^{\circ} \mathrm{C}\right)$ or cold $\left(4^{\circ} \mathrm{C}\right)$ before extracting total RNA. Our northern data shows that heat stress for $3 \mathrm{~h}$ greatly influenced the activation of MoGolS1 transcript in the lemon balm leaves (Figs. 6A and B). Our result was supported by the findings of Panikulangara et al. [2004] who mentioned strong induction of GolS1 gene both in wild type (WT) and heat shock factor3 (HSF3) TPs Arabidopsis plant subjected to heat stress $\left(37^{\circ} \mathrm{C}\right)$ for $2 \mathrm{~h}$. The transcription level of MoGolS1 gene also increased at moderate level in the leaves treated with cold for $12 \mathrm{~h}$ or 1 day. These data supported the

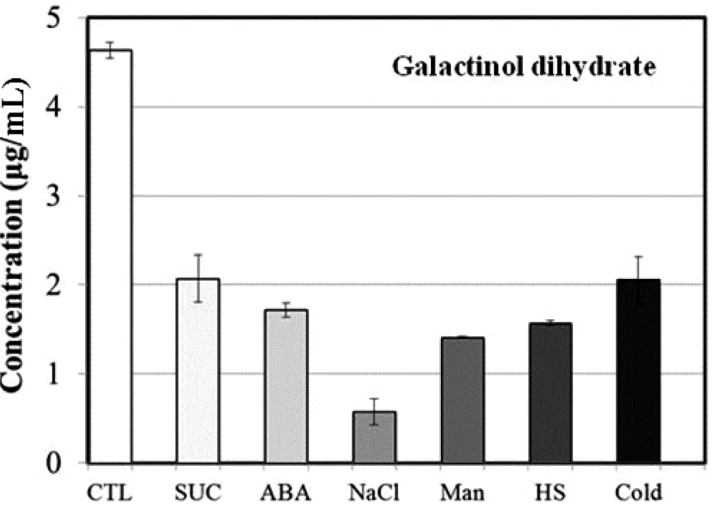

Fig. 8. Quantitation of galactinol dehydrate. For quantitative analysis of galactinol, standard solutions at five concentration levels between 0.05 and $5 \mu \mathrm{g} / \mathrm{mL}$ were used. Linearity of the multi-point calibration curves was determined by plotting the peak area ratios of the analyte using QuanLynx software. The galactinol levels in plant extracts after stress treatment were quantified based on the calibration curve.

findings of Taji et al. [2002], who reported strong induction of $A t G o l S 3$ transcription when Arabidopsis plants were treated with cold for $10-24 \mathrm{~h}$ at $4^{\circ} \mathrm{C}$. Similar result was also reported by Downie et al. [2003] mentioning that tomato galactinol synthase (LeGolSl) gene induction in the leaves of seedlings was maximum when treated with cold $\left(5^{\circ} \mathrm{C}\right)$ for $12 \mathrm{~h}$. The transcription level of MoGolSl gene after 2 days of cold treatment was weak and irregular (Fig. 6A). Similar characteristics of gene expression was observed for $A t G o l S 1$ which strongly induced by the drought, high salinity and weakly by ABA [Taji et al., 2002] and heat shock [Panikulangara et al. 2004] was responsible for the various stress resistance in the Arabidopsis.

In contrast to the enhanced expression of MoGolS1, the concentration of galactinol dehydrate was lower after astress treatment than control (Fig. 8). Their accumulation in plants is associated with stressful environmental conditions such as cold, heat, or dehydration [Santarius, 1973; Santarius and Milde, 1977; Hinesley et al., 1992; Ashworth et al., 1993; Wiemken and Ineichen, 1993; Bachmann et al., 1994; Taji et al., 2002]. We may think of hypotheses to explain these results. Although the MoGolSl gene is induced by abiotic stresses, the level of protein may not be fully fuctional in stress conditions. Or the MoGolSl gene is the only one gene which is responsible for playing a role in producing galactinol dihydrate in $M$. officinalis. Indeed, in our EST analysis we found only one GolS gene which was studied in current study.

In Conclusion, the MoGolSI gene was strongly expressed by the abiotic stress induced by sucrose, $\mathrm{ABA}, \mathrm{NaCl}$, cold or heat shock. However, its level is not enhanced much in response to manitol. The MoGolSl gene induction with various stresses may be possible for its crucial function in abiotic stress tolerance in plants, providing a good engineering target for genetic engineering. 


\section{Acknowledgments}

This work was supported by a grant from Korea Research Foundation (to Hojoung Lee, 2009; Grant \#F00005 and \#F00007).

\section{References}

Ashworth EN, Stirm VE, and Volenec JJ (1993) Seasonal variations in soluble sugars and starch within woody stems of Cornus sericea L. Tree Physiol 13, 379-388.

Bachmann M, Matile P, and Keller F (1994) Metabolism of the raffinose family oligosaccharides in leaves of Ajuga reptans L. cold acclimation, translocation, sink to source transition: Discovery of chain elongation enzyme. Plant Physiol 105, 13351345.

Bohnert H, Nelson DE, and Jensen RG (1995) Adaptations to environmental stresses. Plant Cell 7, 1099-1111.

Bray EA (1997) Plant responses to water deficit. Trends Plant Sci 2 , $48-54$.

Downie BS, Gurusinghe P, Dahal RR, Thacker JC, Snyder H, Nonogaki K, Yim K, Fukanaga V, Alvarado, and Bradford KJ (2003) Expression of a Galactinol Synthase gene in tomato seeds is up-regulated before maturation desiccation and again after imbibition whenever radicle protrusion is prevented. Plant Physiol 131, 1347-1359.

Hinesley LE, Pharr DM, Snelling LK, and Funderburk SR (1992) Foliar raffinose and sucrose in four conifer species: relationship to seasonal temperature. J Am Soc Hortic Sci 117, 852-855.

Ingram J and Bartels D (1996) The molecular basis of dehydration tolerance in plants. Annu Rev Plant Physiol Plant Mol Biol 47, 377-403.

Javed F and Ikram S (2008) Effect of sucrose induced osmotic stress on callus growth and biochemical aspects of two wheat genotypes. Pakistan J Bot 40, 1487-1495.

Kwon Y, Kim SH, Jung MS, Kim MS, Oh JE, Ju HW, Kim K, Vierling E, Lee H, and Hong SW (2007) Arabidopsis hot2 encodes an endochitinase-like protein that is essential for tolerance to heat, salt and drought stresses. Plant J 49, 184-193.

Lee H, Guo Y, Ohta M, Xiong L, Stevenson B, and Zhu JK (2002) LOS2, a genetic locus required for cold-responsive gene transcription encodes a bifunctional enolase. EMBO J 21, 26922702.

Liu JJ, Odegard W, and de Lumen BO (1995) Galactinol synthase from kidney bean cotyledon and zucchini leaf: Purification and Nterminal sequences. Plant Physiol 109, 505-511.

Nagira Y, Ikegami K, Koshiba T, and Ozeki Y (2006) Effect of ABA upon anthocyanin synthesis in regenerated torenia shoots. J Plant Res 119, 137-144.
Nishizawa A, Yabuta Y, and Shigeoka S (2008) Galactinol and raffinose constitute a novel function to protect plants from oxidative damage. Plant Physiol 147, 1251-1263.

Panikulangara TJ, Eggers-Schumacher G, Wunderlich M, Stransky H, and Schoffl F (2004) Galactinol synthase1. A novel heat shock factor target gene responsible for heat-induced synthesis of raffinose family oligosaccharides in Arabidopsis. Plant Physiol 136, 3148-3158.

Peterbauer T and Richter A (2001) Biochemistry and physiology of raffinose family oligosaccharides and galactosyl cyclitols in seeds. Seed Sci Res 11, 185-197.

Pridham JB and Hassid WZ (1965) Biosynthesis of raffinose. Plant Physiol 40, 984-986.

Santarius KA (1973) The protective effect of sugars on chloroplast membranes during temperature and water stress and its relationship to frost, desiccation and heat resistance. Planta 113, 105-114.

Santarius KA and Milde H (1977) Sugar compartmentation in frosthardy and partially dehardened cabbage leaf cells. Planta 136, 163-166.

Saravitz DM, Pharr DM, and Carter TE (1987) Galactinol synthase activity and soluble sugars in developing seeds of four soybean genotypes. Plant Physiol 83, 185-189.

Shinozaki K and Yamaguchi-Shinozaki K (1997) Gene Expression and signal transduction in water-stress response. Plant Physiol 115, 327-334.

Smith PT, Kuo TM, and Crawford CG (1991) Purification and characterization of galactinol synthase from mature zucchini squash leaves. Plant Physiol 96, 693-698.

Sprenger N and Keller F (2000) Allocation of raffinose family oligosaccharides to transport and storage pools in Ajuga reptans: the roles of two distinct galactinol synthases. Plant J 21, 249-258.

Taji T, Ohsumi C, Iuchi S, Seki M, Kasuga M, Kobayashi M, Yamaguchi-Shinozaki K, and Shinozaki K (2002) Important roles of drought- and coldinducible genes for galactinol synthase in stress tolerance in Arabidopsis thaliana. Plant J 29, 417-426.

Takanashi K, Shitan N, Sugiyama A, Kamimoto Y, Hamamoto M, Iwaki T, Takegawa K, and Yazaki K (2008) Galactinol synthase gene of Coptis japonica is involved in berberine tolerance. Biosci Biotechnol Biochem 72, 398-405.

Wiemken V and Ineichen K (1993) Effect of temperature and photoperiod on the raffinose content of spruce roots. Planta 190, 387-392.

Zhao TY, Martin MD, Meeley RB, and Downie B (2004) Expression of the maize galactinol synthase gene family: (II) Kernel abscission, environmental stress and myo-inositol influences accumulation of transcript in developing seeds and callus cells. Physiol plant 121, 647-655. 